\title{
Characterization by Photocurrent Spectroscopy of Anodic Films Formed on Tin-Indium Alloys
}

\author{
Carlos Moina and Gabriel Ybarra* \\ Instituto Nacional de Tecnología Industrial, C.C. 157, (B1650WAB) San Martín, Argentina
}

Received 2 March 2009; accepted 19 November 2009

\begin{abstract}
In the present work, a study of the photoelectrochemical characteristics and chemical structure of anodic films formed onto different $\operatorname{Sn}_{1-\mathrm{x}} \operatorname{In}_{\mathrm{x}}(0 \leq \mathrm{x}<0.3)$ alloys in $0.2 \mathrm{M}$ $\mathrm{NaOH}$ is presented. The electrochemical behavior of the alloys was studied by means of cyclic voltammetry. The optical band gaps of the passive films were determined by photocurrent spectroscopy, while its chemical structure was studied by Fourier transform infrared reflection-absorption spectroscopy. The experimental results indicate that the anodic films consist of hydroxylated species of the type $\operatorname{In}_{\mathrm{y}} \operatorname{Sn}_{(1-\mathrm{y})}(\mathrm{OH})_{4-\mathrm{y}}$. The films are enriched in In and, for $x>0.25, \operatorname{In}(\mathrm{OH})_{3}$ is the dominant component of the surface layers. The existing theoretical background was used to estimate the relative concentration of $\mathrm{Sn}$ and In in the films from the band gap measurements..
\end{abstract}

Keywords: tin-indium alloys, passive layers, photocurrent spectroscopy, infrared spectroscopy.

\section{Introduction}

Anodically formed passive layers usually behave as disordered materials whose electronic characteristics can be described by general theories that were developed for amorphous semiconductors [1]. However, this approach somehow misses the link between the semiconducting properties and the chemical nature of the films. Only recently, some semiempirical correlations between optical band gaps of passive films and the electronegativity of their components have been worked out $[2,3]$. This approach has been successfully applied to study the correlation between semiconducting properties and the hydroxylation degree of passive films grown onto tin electrodes at several $\mathrm{pH}$ values [4].

For anodic films formed onto metallic alloys, additional complications arise when the passive layer is enriched in one or more of the components of the alloy.

\footnotetext{
* Corresponding author. E-mail address: gabriel@inti.gob.ar
} 
In these cases additional information of the chemical composition of the films is needed in order to fully correlate the film structure with its electronic properties. In the present work, a study of the photoelectrochemical characteristics and chemical structure of anodic films formed onto different $\operatorname{Sn}_{1-\mathrm{x}} \operatorname{In}_{\mathrm{x}}$ alloys, with $0 \leq$ $\mathrm{x}<0.3$, in $0.2 \mathrm{M} \mathrm{NaOH}$ is presented. These films behave as heavily doped $n$-type semiconductors $[5,6]$. The electrochemical behavior of the alloys was studied by means of cyclic voltammetry, ex situ reflection-absorption Fourier transform infrared spectroscopy has been employed to explore the chemical structure of the films, and photocurrent spectroscopy has been used to determine the optical band gap of the passive layers.

\section{Experimental}

Tin (99.999 \%, Koch-Light) and indium (99.999 \%, Johnson Matthey Chemicals Ltd.) were employed to produce the binary alloys of uniform composition used in the working electrodes, by melting the metals under vacuum conditions. Working electrodes consisted of disks with a diameter of $3.0 \mathrm{~mm}$ embedded in PTFE holders. The metal surfaces were polished with 1200 grade corundum (Buehler) and thoroughly rinsed with three-folded distilled water. Prior to the electrochemical and photoelectrochemical experiments, the electrodes were cathodized during $15 \mathrm{~min}$ at potentials located in the hydrogen evolution reaction to remove traces of surface oxides. Then, the anodic layers were grown at the formation potential of $+1.00 \mathrm{~V}$ for $90 \mathrm{~min}$.

Electrochemical and photoelectrochemical measurements were carried out in 0.2 $\mathrm{M} \mathrm{NaOH}$ solution, which was prepared from analytical grade (Merck) reagents and distilled water, at $25{ }^{\circ} \mathrm{C}$ under purified $\mathrm{N}_{2}$ gas saturation conditions. In the photoelectrochemical experiments, chopped monochromatic light from an XBO 150W xenon arc lamp was employed to illuminate the electrode. Potentials were controlled with a PAR 273A potentiostat, and the photocurrent was separated from the base current using a Stanford Research Instruments 850 lock-in amplifier. Potentials were measured and referred to in the text against a $\mathrm{Hg}|\mathrm{HgO}| 0.2 \mathrm{M} \mathrm{NaOH}$ reference electrode. The light from the lamp was monochromated with an Oriel monochromator and collimated by means of a system of quartz lenses. The monochromatic light illuminated the working electrode through a quartz window. The power of the incident light was about 0.1 $\mathrm{mW} \mathrm{cm}{ }^{-2}$.

Ex situ reflection-absorption Fourier transform infrared spectra were collected in a Nicolet Magna 550 Series II spectrometer. A MCT detector was used throughout the measurements. The electrodes were anodized at the growth potential, rinsed with three-fold distilled water, dried under $\mathrm{N}_{2}$ current and immediately allocated in a holder designed to fit in a VeeMax (SpectraTech) specular reflection stage at an incidence angle of $30^{\circ}$. Absorbance was expressed in arbitrary Kubelka-Munk units. 


\section{Results}

\section{Cyclic voltammetry}

The cyclic voltammograms of $\mathrm{Sn}$, In and $\mathrm{Sn}_{0.925} \mathrm{In}_{0.075}$ electrodes in $\mathrm{NaOH} 0.2 \mathrm{M}$ are shown in Fig. 1. As has been concluded in a previous work [4], a dissolution/precipitation mechanism is responsible for the growth of oxyhydroxide films on the electrodes. Characteristic peaks due to the dissolution of Sn (broad peaks in the range between -1.05 and $-0.6 \mathrm{~V}$, in Fig. 1a) [4] and In (peak around $-1.2 \mathrm{~V}$, in Fig. 1b) [5] are clearly seen. On the other hand, the cyclic voltammogram of the $\mathrm{Sn}_{0.925} \mathrm{In}_{0.075}$ alloy (Fig. 1c) shows two anodic peaks at $-1.2 \mathrm{~V}$ and $-1.1 \mathrm{~V}$ that can be assigned to the formation of $\mathrm{In}^{+3}$ and $\mathrm{Sn}^{+4}$ species, respectively [6]. By comparing the cyclic voltammograms presented in Fig. 1a and 1c is apparent that, in presence of In, the dissolution of Sn is somehow inhibited. This is in agreement with previous reports in which it was found that, as the concentration of In in the alloys was increased, the charge under the tin dissolution peaks diminished and became negligible small for In concentration in the alloy higher than $25 \%$ [6].
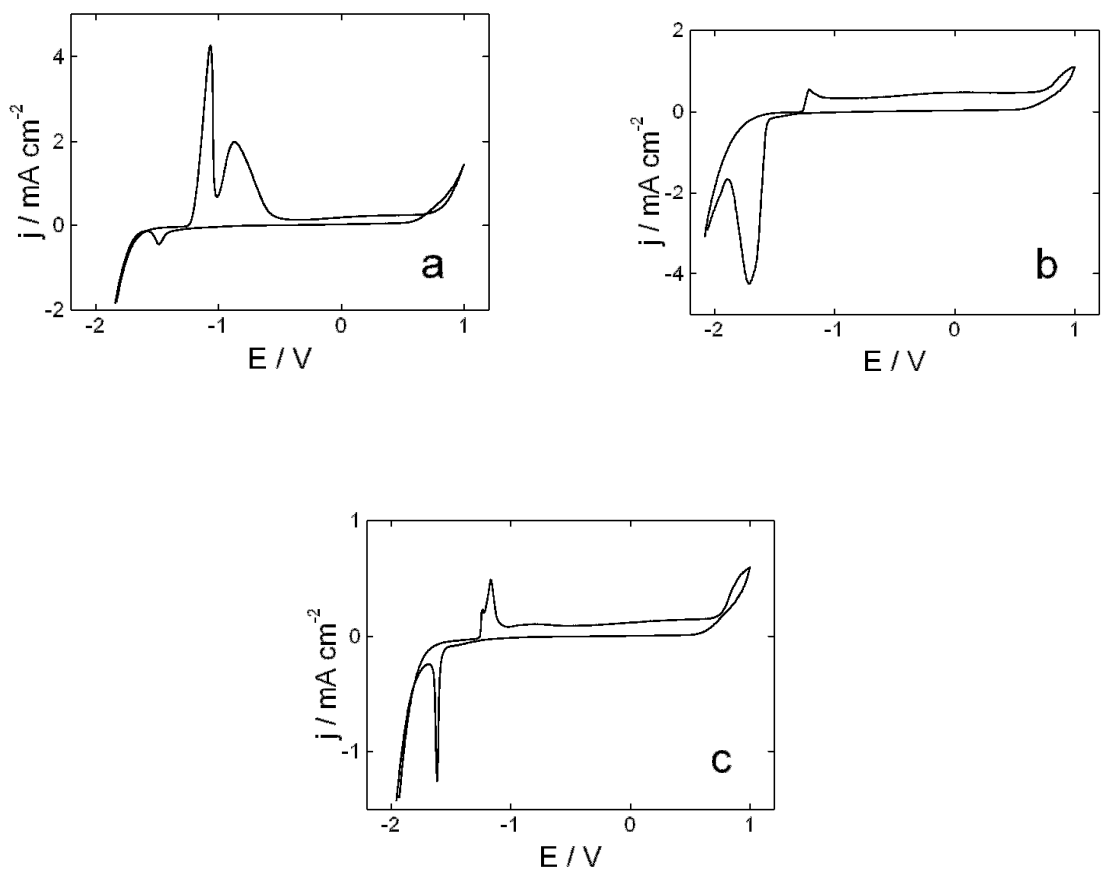

Figure 1. Cyclic voltammograms of anodic films formed on $\mathrm{Sn}(\mathbf{a})$, In (b), and $\mathrm{Sn}_{0.925} \operatorname{In}_{0.075}(\mathbf{c})$, in $\mathrm{NaOH} 0.2 \mathrm{M} . \mathrm{v}=0.02 \mathrm{~V} \mathrm{~s}^{-1}$.

\section{Photocurrent spectroscopy}

Fig. 2a shows the normalized photocurrent spectra of anodic films formed on the $\mathrm{Sn}_{1-\mathrm{x}} \mathrm{In}_{\mathrm{x}}$ electrodes in $0.2 \mathrm{M} \mathrm{NaOH}$. All observed photocurrents were anodic, as expected for n-type semiconductors in these conditions. The onset of photocurrent depended on the In content in the alloys, and displaced to higher photon energies as the In content was increased. The different spectra depicted a similar shape, going through a broad maximum beyond which the photocurrent 
decreased. The passive films displayed photoresponses characteristic of amorphous n-type semiconductors [6,7]. In these materials the absorption coefficient of the optical transitions between extended states usually follows a power law of the type [8]:

$$
\alpha(v) \propto \frac{\left(h v-E_{g}\right)^{n}}{h v}
$$

where $\mathrm{E}_{\mathrm{g}}$ represents the optical or mobility gap, $\mathrm{h} v$ the incident photon energy, and $\alpha$ the absorption coefficient. The exponent $\mathrm{n}$ depends on the particular distribution of the density of states [1]. In general, $n=2$ is considered, which corresponds to a parabolic distribution of states [10]. If the photocurrent $i_{p h}$ is considered proportional to the absorption coefficient, the following expression is obtained:

$$
\sqrt{\mathrm{i}_{\mathrm{ph}} \mathrm{hv}} \propto\left(\mathrm{hv}-\mathrm{E}_{\mathrm{g}}\right)
$$

Eq. 2 has been widely used for the determination of the mobility gaps of disordered materials [2-9], which is obtained as the intercept with the abscises in $\mathrm{a}\left(\mathrm{i}_{\mathrm{ph}} \mathrm{h} v\right)^{1 / 2}$ vs. hv graph. These graphs are called Tauc's plots, and are shown in the inset of Figure 2a for anodic films formed on Sn, In, and a Sn-In alloy. Figure 2b depicts the variation of the estimated mobility gaps as a function of the In content in the alloys. The mobility gaps of the films varied monotonically from $2.20 \mathrm{eV}$ for pure $\mathrm{Sn}$ to $2.70 \mathrm{eV}$ for $\mathrm{Sn}_{0.75} \mathrm{In}_{0.25}$. This value is quite close to that of films formed onto pure In in the same electrolyte $\left(\mathrm{E}_{\mathrm{g}} \cong 2.9 \mathrm{eV}\right)$.
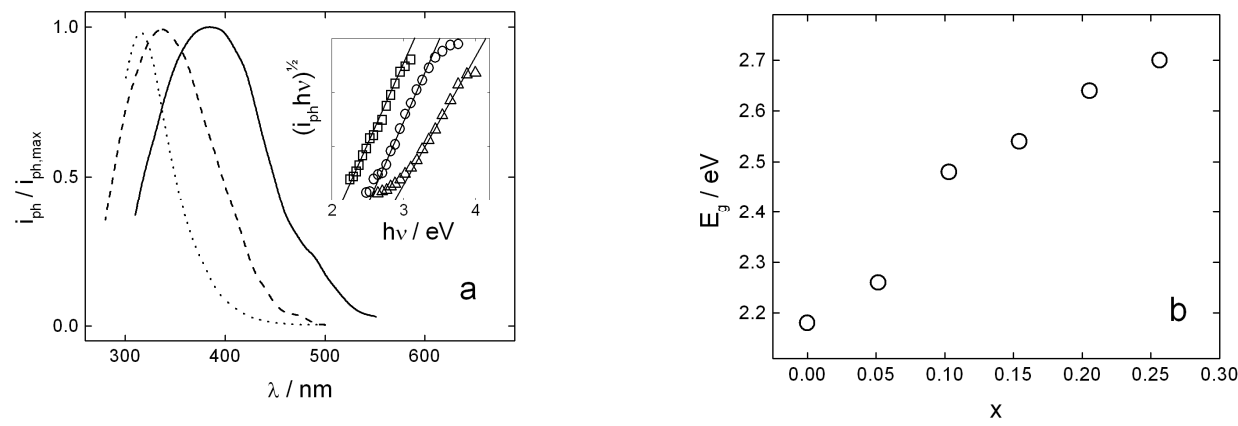

Figure 2. a) Photocurrent spectra of anodic films grown on $\mathrm{Sn}(-), \operatorname{Sn}_{0.9} \operatorname{In}_{0.1}(---)$ and In $(\cdots \cdots \cdots \cdot)$, with an inset of the corresponding Tauc's plots for $S n(\square), \operatorname{Sn}_{0.9} \operatorname{In}_{0.1}$ $(O)$, and $\operatorname{In}(\triangle)$. b) Influence of the indium content in the $\operatorname{Sn}_{1-\mathrm{x}} \operatorname{In}_{\mathrm{x}}$ alloy on the optical band gap obtained for the passive films.

\section{Infrared spectroscopy}

Fig. 3 shows the ex situ absorption-reflection infrared spectra in the 2000-400 $\mathrm{cm}^{-1}$ range of anodic films grown on $\mathrm{Sn}(\mathrm{a})$, In (b), and an alloy with $7.5 \%$ In (c). The infrared spectra obtained for the anodic layers formed on $\mathrm{Sn}$ in $0.2 \mathrm{M} \mathrm{NaOH}$ have been discussed with a certain detail elsewhere [4], where the spectral features have been explained on the basis that the composition of the films can be regarded as $\mathrm{Sn}(\mathrm{OH})_{4}$ with a high content of lattice water. The strong bands due to 
$\mathrm{O}-\mathrm{Sn}-\mathrm{O}$ and $\mathrm{Sn}-\mathrm{O}$ vibrations in the wave numbers range between 800 and 500 $\mathrm{cm}^{-1}$ dominate the spectrum. The band at around $1640 \mathrm{~cm}^{-1}$ can be assigned to the deformation mode $(\delta)$ of the $\mathrm{H}-\mathrm{O}-\mathrm{H}$ bond of water.

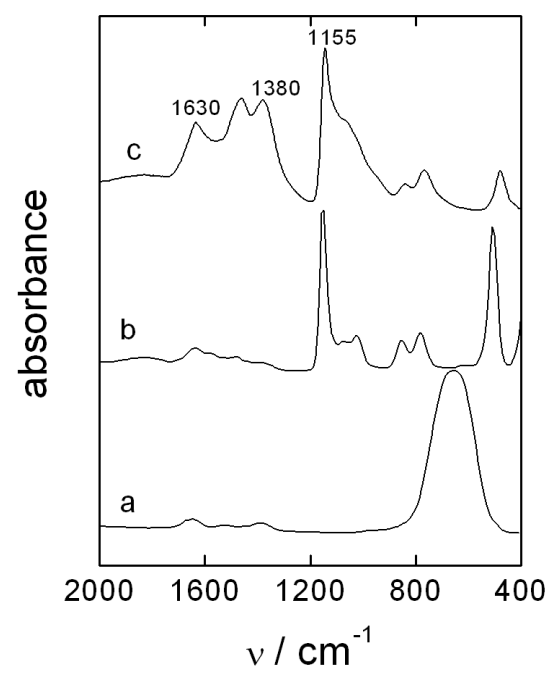

Figure 3. Infrared spectra of anodic films formed on $\mathrm{Sn}(\mathrm{a})$, In (b), and $\mathrm{Sn}_{0.925} \operatorname{In}_{0.075}$ (c), in $\mathrm{NaOH} 0.2 \mathrm{M}$.

The spectral features found for the passive film formed on In, shown in Fig. 3b, are in accordance with that reported for $\operatorname{In}(\mathrm{OH})_{3}$ species. The formation of $\mathrm{In}(\mathrm{OH})_{3}$ in anodic films on In has been reported before [7]. The most prominent band, observed at $1150 \mathrm{~cm}^{-1}$, can be assigned to the deformation mode $\delta(\mathrm{OH})$ of terminal hydroxyl group of In-OH [9-12], while the band at around $1100 \mathrm{~cm}^{-1}$ can been assigned to the $\delta(\mathrm{OH})$ mode of bridging hydroxyl groups [13].

Fig. 3c shows that as little In content in the alloy as $7.5 \%$ induces profound changes in the composition of the passive layer. Noticeably, the bands due to the main vibration modes of $\mathrm{Sn}$ compounds almost vanish, and the spectrum is dominated by the vibration modes of In species. It is also seen that the intensity ratio of the bands at $1160 \mathrm{~cm}^{-1}$ and $1100 \mathrm{~cm}^{-1}$ increases. This behavior has been reported before [13] and has been assigned to a decrease of the bridging hydroxyl groups, due to a sharing of $\mathrm{OH}$ groups with $\mathrm{Sn}$. This interpretation is reinforced by the appearance of two bands at around 1385 and $1400 \mathrm{~cm}^{-1}$, which has been assigned to deformation modes of $\mathrm{OH}$ groups bonded to $\mathrm{In}^{3+}$ and $\mathrm{Sn}^{4+}$, respectively [13]. These new deformation modes may indicate that a strained network of hydroxylated species is formed in the passive film. The relative areas due to the modes associated to tin species diminished as the concentration of indium increased. For In concentrations higher than $20 \%$, the strong In-OH bands totally obscured that of $\mathrm{Sn}-\mathrm{OH}$ modes.

\section{Discussion}

Photocurrent spectroscopy has been widely used to obtain in situ information of passive layers [2-8]. The most important property measured by photocurrent spectroscopy is the optical band gap for semiconductor passive films. Variations 
of band gap values have been observed in several systems of technological interest. These variations in band gap values may have different origins, such as changes in the composition, the crystalline or amorphous nature, and the size of crystalline particles.

Considerable efforts have been made in order to establish correlations between the value of the band gap and the composition of the films. The relationship between the bond strength and band gap value has been discussed by Vijh for oxide semiconductors [13] and by Ovshinsky in the case of amorphous semiconductors [14]. More recently, Di Quarto et al. [2,3] proposed a correlation between the optical band gap and the electronegativities $X_{O}$ and $X_{M}$ of the anionic and cationic groups in metallic oxides, which was later extended to include ternary oxides, hydroxides, and oxyhydroxides formed onto different electrodes: Co [15], Al alloys [16], Mg [17], Ti alloys [18], Fe [19], Hf and Hf$\mathrm{W}$ alloys [20], and $\mathrm{Cr}$ [3].

For a compound with a general formula of the type $B_{b} A_{a}$, where $B$ and $A$ represent groups with cationic and anionic character respectively, the following relationship was derived:

$$
\mathrm{E}_{\mathrm{g}}=\mathrm{k}_{1}\left(\mathrm{X}_{\mathrm{an}}-\mathrm{X}_{\mathrm{cat}}\right)^{2}+\mathrm{k}_{2}
$$

where $X_{a n}$ and $X_{c a t}$ are the average electronegativities of the anionic and cationic groups, whose values are calculated as the arithmetic mean between the elements forming the groups. In the cases in which those correlations apply, photocurrent spectroscopy could be employed as an analytical tool to provide an insight of the composition of complex systems, which cannot be easily studied in situ by other analytical techniques.

As has been established before [4], the value of the band gap and the infrared spectral features of films formed on Sn, indicate that its composition can be regarded as $\mathrm{Sn}(\mathrm{OH})_{4}$, while the experimental evidence shows that the films formed on pure In electrodes are composed by $\operatorname{In}(\mathrm{OH})_{3}$ species. Fig. 4 shows that the obtained band gaps of $\operatorname{In}(\mathrm{OH})_{3}$ and $\mathrm{Sn}(\mathrm{OH})_{4}$ fit the general trend of other s-p metal hydroxides previously reported [3].

In the case of the Sn-In alloys, the photocurrent spectra depicted in Fig. 2 show that the passive films present a single absorption edge. On the other hand, the infrared spectra indicate that the films are composed by an In and $\mathrm{Sn}$ mixed hydroxide, whose chemical formula can be expressed as $\operatorname{In}_{\mathrm{y}} \operatorname{Sn}_{1-\mathrm{y}}(\mathrm{OH})_{4-\mathrm{y}}$. This conclusion is also supported by an electrochemical impedance study carried out in similar experimental conditions [6]. Thus, if we consider, based on the photoelectrochemical and infrared spectroscopy results, that films grown on InSn alloys are composed by a Sn-In mixed hydroxide, then the average electronegativity of the anionic group is $\mathrm{X}_{\mathrm{OH}}=\left(\mathrm{X}_{\mathrm{O}}+\mathrm{X}_{\mathrm{H}}\right) / 2$, and that of the cationic group is $\mathrm{X}_{\mathrm{cat}}=\mathrm{y} \mathrm{X}_{\mathrm{In}}+(1-\mathrm{y}) \mathrm{X}_{\mathrm{Sn}}$. Assuming a value of $2.90 \mathrm{eV}$ for the band gap of $\operatorname{In}(\mathrm{OH})_{3}$ (which corresponds to $\mathrm{y}=1$ ) and $2.20 \mathrm{eV}$ for $\mathrm{Sn}(\mathrm{OH})_{4}(\mathrm{y}=$ 0), Eq. 3 can be worked out to give:

$$
E_{g} / e V=2.20+0.67 \cdot y+0.03 \cdot y^{2}
$$


where the following values for the electronegativity of the elements in the Pauling scale were employed: $\mathrm{X}_{\mathrm{O}}=3.44, \mathrm{X}_{\mathrm{H}}=2.20, \mathrm{X}_{\mathrm{Sn}}=1.96$, and $\mathrm{X}_{\mathrm{In}}=1.78$ [21].

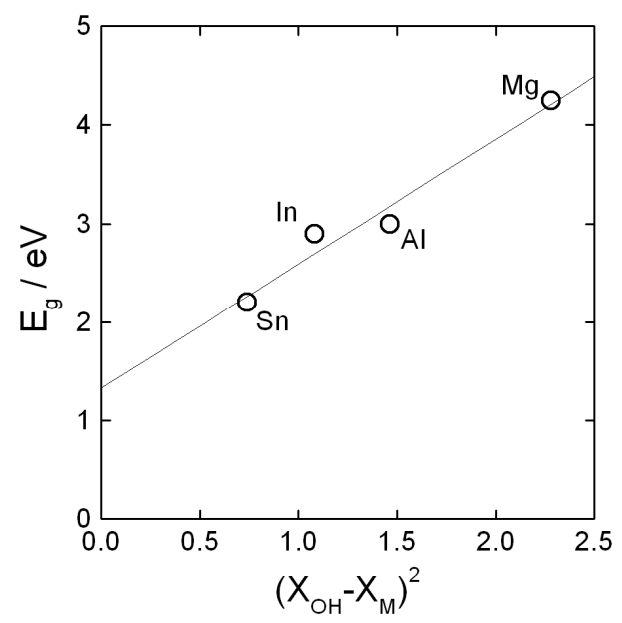

Figure 4. Relationship between the band gap of s-p metal hydroxides and the square of electronegativity difference. The band gap values for $\mathrm{Mg}$ and $\mathrm{Al}$ hydroxides were taken from Ref. 3.

The last term in Eq. 3 is practically negligible for moderate In content, so that the quadratic equation can be approximated to a linear one. Assuming that the composition is constant throughout the film, Eq. 3 can be employed to calculate the In:Sn ratio inside the passive layers grown on the different alloys. The results are shown in Fig. 5. A higher content of In in the films as compared to that of the alloys is clearly appreciated. The enrichment of In species in the passive layers is in accordance with the results obtained by means of infrared spectroscopy and cyclic voltammetry. It is emphasized that, in the system investigated, experimental results obtained by photocurrent spectroscopy were employed to quantitatively relate the composition of an alloy with that of the anodic film formed on it, which is a subject of considerable interest (see, for instance, Ref. 22).

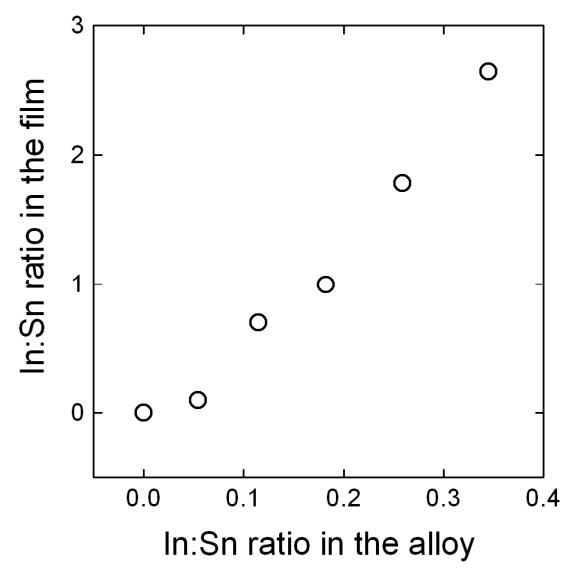

Figure 5. In to Sn ratio in the film calculated according to Eq. 4 vs. In to $\mathrm{Sn}$ ratio in the alloy. 


\section{Conclusions}

The experimental results presented in this work indicate that the anodic passive films obtained on $\operatorname{Sn}_{1-\mathrm{x}} \operatorname{In}_{\mathrm{x}}$ alloys in alkaline electrolytes consisted of hydroxylated species of the type $\operatorname{In}_{\mathrm{y}} \mathrm{Sn}_{(1-\mathrm{y})}(\mathrm{OH})_{4-\mathrm{y}}$. The films behave as amorphous n-type semiconductors and their photoelectrochemical behavior is related to the film composition.

The results obtained by cyclic voltammetry and infrared spectroscopy showed that the films were enriched in In. From the optical gap measurements, obtained by photocurrent spectroscopy, the degree of In enrichment relative to the composition of the alloy was estimated. For In content in the alloy higher than $25 \%, \operatorname{In}(\mathrm{OH})_{3}$ is the dominant component of the layers. The present work shows that by combining results provided by electrochemical measurements, infrared spectroscopy and photocurrent spectroscopy, valuable information relating the chemical structure and the semiconducting properties of thin anodic films can be obtained.

\section{References}

1. N.F. Mott, E.A. Davies, "Electronic Processes in Non-Crystalline Materials," Clarendon Press, Oxford, 1979.

2. F. Di Quarto, C. Sunseri, S. Piazza, M.C. Romano, J. Phys. Chem. B 101 (1997) 2519.

3. S. Piazza, M. Santamaria, C. Sunseri, F. Di Quarto, Electrochim. Acta 48 (2003) 1105.

4. C.A. Moina, G.O. Ybarra, J. Electroanal. Chem. 504 (2001) 175.

5. M. Metikoš-Huković, S. Omanović, J. Electroanal. Chem. 455 (1998) 181.

6. U. Stimming, Electrochim. Acta 31 (1986) 415.

7. $\quad$ L.M. Peter, Ber. Bunsenges. Phys. Chem. 91 (1987) 419.

8. G.A. Connell, in Amorphous Semiconductors, M.H. Brodsky (Ed.), Springer, Berlin, 1985.

9. K. Nakamoto, "Infrared and Raman Spectra of Inorganic and Coordination Compounds," $4^{\text {th }}$ Ed., John Wiley \& Sons, New York, 1992.

10. W.H. Ho and S.K. Yen, Thin Solid Films 498 (2006) 80.

11. N.C. Pramanik, S. Das, P.K. Biswas, Mat. Letters 56 (2002) 671.

12. S.K. Poznyak, A.I. Kulak, Electrochim. Acta 45 (2000) 1595.

13. A.K. Vijh, in "Oxides and oxide films," vol. 2, J.W. Diggle Ed., New York, 1973.

14. S.R. Ovshinsky, in "Physical properties of amorphous materials," D. Adler, B.B. Schwartz and M.C. Steele, Eds., Plenum Press, New York, 1985.

15. M. Santamaria, E. Adragna, F. Di Quarto, Electrochem. Solid-State Lett. 8 (2005) B12.

16. M. Santamaria, F. Di Quarto, P. Skeldon, G.E. Thompson, J. Electrochem. Soc. 153 (2006) B518.

17. L. Anicai, R. Masi, M. Santamaria, F. Di Quarto, Corrosion Sci. 47 (2005) 2883. 
18. N.T.C. Oliveira, S.R. Biaggio, S. Piazza, C. Sunseri, F. Di Quarto, Electrochim. Acta 49 (2004) 4563.

19. S. Piazza, M. Sperandeo, C. Sunseri, F. Di Quarto, Corrosion Sci. 46 (2004) 831.

20. F. Di Quarto, M. Santamaria, P. Skeldon, G.E. Thompson, Electrochim. Acta 48 (2003) 1143.

21. A.L. Allred, J. Inorg. Nucl. Chem. 17 (1961) 215.

22. H. Habazaki, K. Simizu, P. Skeldon, G.E. Thompson, G.C. Wood, Corrosion Sci. 39 (1997) 339. 